\title{
Analytical model for determining the influence of support flexibility on shear capacity of hollow core slabs
}

\author{
Mateusz Surma ${ }^{1, *}$, Wit Derkowski ${ }^{1}$, and Andrzej Cholewicki ${ }^{2}$ \\ ${ }^{1}$ Institute of Building Materials and Structures, Faculty of Civil Engineering, Cracow University of Technology, Warszawska Street 24, \\ 31-155 Krakow, Poland \\ ${ }^{2}$ Building Research Institute, Filtrowa Street 1, Warszawa, Poland
}

\begin{abstract}
The paper presents the authors' model of calculating the shear capacity of prestressed concrete hollow core slabs in Slim Floor structures, the theoretical basis of which is Cholewicki's two-beam model and the Finnish model by Pajari and Leskelä. The purpose of the model development was to find an alternative method for determining the horizontal tangential stress $\tau_{\mathrm{zx}}$ which occurrence is decisive for reducing the shear resistance of channel slabs based on flexible supports. The model gives intermediate results between the Finnish model and the German model by Hegger and Roggendorf, which seems to be desirable, taking into account the conservative character of the Finnish model. The authors' model is the first attempt to date at analytical consideration of the effect of web flexibility which may be important to maintaining an adequate capacity of the slab. In other models, the webs are treated as a rigid system, connecting the horizontal flanges of the slab. The model is a simple calculation tool, available to Slim Floor designers for an engineering analysis.
\end{abstract}

\section{Introduction}

Significance and a multifaceted aspect of shear capacity of prestressed concrete hollow core (HC) slabs resting on the so-called flexible supports which are slim steel I beams or composite hat-section beams in Slim Floor structures have been commented by the paper authors in recent years in Polish technical and science literature, i.a. in $[1,2,3,4,5,6,7,8]$. The papers pick up the issues connected with the influence of the reinforced topping layer and the location of the HC slabs on the floor on the change of the shear capacity. The authors consider also the complex stress state in prestressed HC slabs because of the torsion effect and the unintended effect of fixing the slabs on the support and also concrete strength and elasticity of precast thin-walled elements (HCs' webs). To date, there are no national guidelines (except an informative instruction from the Building Research Institute [9]) that could really help designers in solving this design problem. In such situation it makes sense to refer to the EN 1168 standard [10] that deals directly with hollow core slabs, however the standard has only a brief comment to the effect that in case of flexible supports, a reduction of shear strength should be taken into account in the support area as a result of horizontal shear stresses. Absence of a clear dimensioning procedure often entices the designers to roughly over-dimension the sections of $\mathrm{HC}$ slabs or to reduce the support spans (leading to a denser grid of supports, and as a result more difficult arrangement of usable space) in order to avoid the results of the so-called "transversal behaviour" of slabs and the need to determine the shear strength reduction. This issue seems particularly important in case of floors made of short-span slab and exposed to high loads, e.g. concentrated forces or a linear load, in the support area.

Two analytical models based on conclusions from experimental studies are widely used in Europe: composite beam model by Pajari and Leskelä $[11,12]$ which is the basis for the Finnish standard [13] and the fib recommendations [14], and the German model by Hegger and Roggendorf stemming from a different theoretical approach [15]. The Finnish model, albeit accessible in engineering calculations, seems to be a conservative tool, according to which the shear capacity is lowered which makes the structure overdimensioned. On the other hand, the German model's procedure is not easily applicable due to quite complicated shape functions for a substitute slab cross section. Its use, without an implementation in software or a table of critical parameters for various slab types (which has been successfully achieved by prefab manufacturers in Germany, see [16]), is essentially problematic.

Shortcomings of both models were the reason to develop an analytical model of our own. Before its basis and calculation procedure will be given, it is necessary to present briefly the main mechanisms of the $\mathrm{HC}$ slab behaviour in Slim Floor structures (see also Fig. 1):

- as the support deflection increases as a result of loads after concreting longitudinal connections between slabs, the slab deformation starts leading to transversal behaviour of a composite floor system in the support's longitudinal plane;

Corresponding author: surma.mat@gmail.com 
- when the limit specified support deflection is exceeded, the slabs tend to move along the support's longitudinal axis, however as a result of composite action in longitudinal locks between slabs and transversal slabsupport connections this is counteracted by adhesion and/or friction forces, the result being additional develop a new analytical model to determine the shear capacity of hollow core slabs on flexible supports.

\section{Authors model for shear capacity of hollow core slabs on flexible supports}

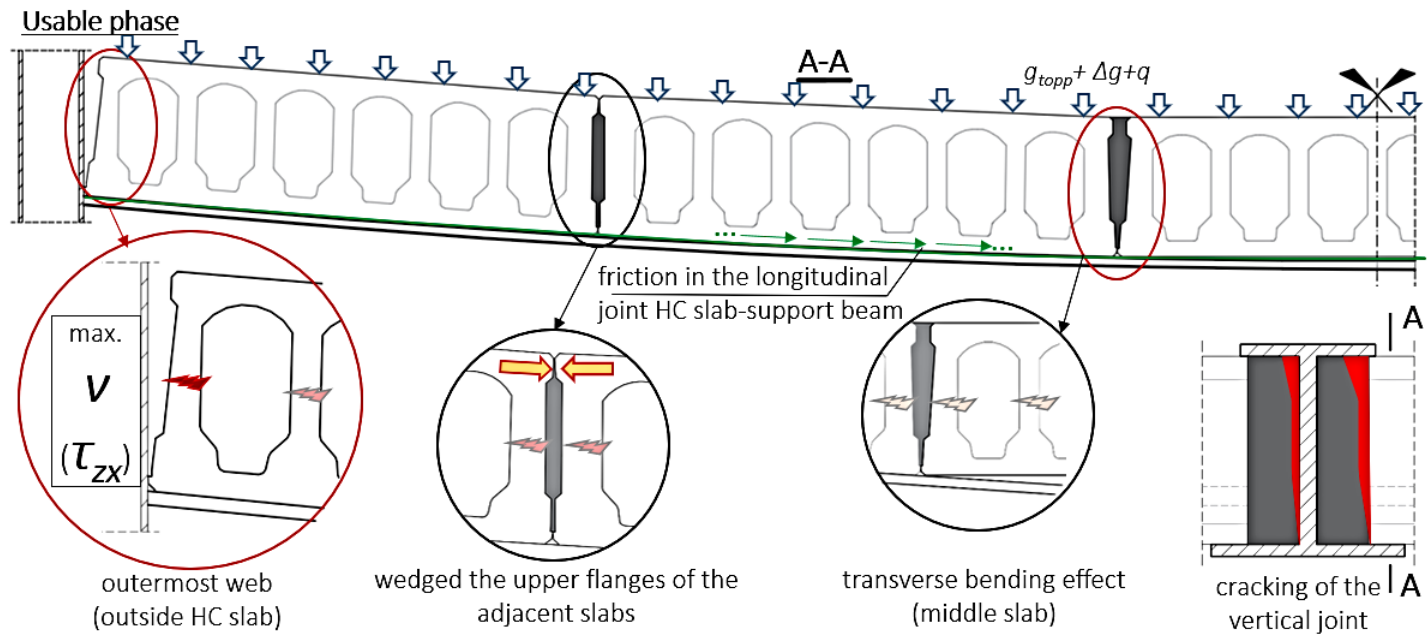

Fig. 1. Mechanism of transverse behaviour of HC slabs supported on a flexible support.

horizontal shear stress $\tau_{\mathrm{zx}}$ in the slab's webs;

- occurrence of a complex stress state (see Fig. 2) causes an increase of main tension stress $\sigma 1$ which leads to diagonal cracking on the outermost web of the last slab of the floor field at the shear force $\mathrm{V}_{\mathrm{Ed}}$ even up to $60 \%$ less than in case of a rigid support (stocky beam or wall);

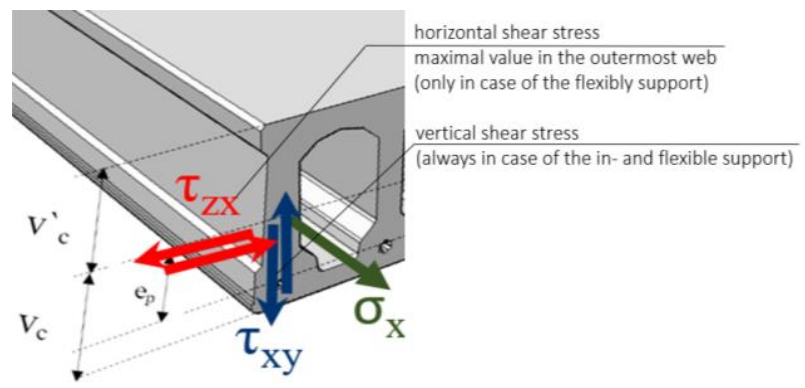

Fig. 2. Complex state of stress in the outermost HC webs.

- diagonal cracking is equivalent to reaching the limit state of shear capacity of an element because, due to technological limitations, the $\mathrm{HC}$ slabs do not have transversal reinforcement in the form of stirrups;

- unlike slabs resting on rigid supports, shear strength of hollow core slabs on flexible supports isn't a sum of shear strengths of individual webs, and the measure of slab safety is the strength of the most loaded web.

In addition, it should be noted that discussion on accepting a uniform methodology for dimensioning of prestressed concrete HC slabs subjected to shear, with a particular emphasis on support flexibility, taking place among European scientists and designers is now very intense. This reason, along with shortcomings of the Finnish and German models and the absence of a Polish regulations or instructions, has induced the authors to
The main goal of the model is to determine close-to-actual values of the horizontal shear stress $\tau_{\mathrm{zx}}$ which occurrence is the main determinant of shear capacity reduction. The theoretical basis is Cholewicki's so-called "two-beam method" for composite structures. The two-beam model assumes the flexible joint between the bands (strands), and the difference between the flexible and rigid connection includes dissimilar normal stress in cross section, a different distribution of unit shearing forces in the connection cross section, and greater deflection values of the bent cross section [9]. The analysis of vertical joint between the face of $\mathrm{HC}$ slab and the support, in which the opening of the crack of the slab and the support determines the flexible features of the whole connection, is described in [16].

Horizontal forces in the slab cross section, parallel to the vertical slab-support joint, are calculated in order to determine horizontal shear stress $\tau_{\mathrm{xz}}$. This method also accounts for impact of flexibility of concrete webs and of the support resulting from the elasticity of the divider material between the slab and the support on variation of shear capacity in prestressed concrete hollow core slabs. The model has been developed based on the following assumptions:

\section{- Assumption 1}

Behaviour of a composite structure is analysed on the system made up of the lower strand (1) (support) and the upper strand (2) which comprises the top flanges of the slab subjected to compression (see Fig. 3). Axial spacing of the strands between their centres of gravity is " $a$ ". Stiffness and elasticity parameters of the strands are defined by the following values: modulus of elasticity $E_{1}$ and $E_{2}$, cross section areas $A_{1}$ and $A_{2}$, and moments of inertia $I_{1}$ and $I_{2}$, for strand (1) and (2), respectively. Unit forces between strands are transmitted via the webs of 
hollow core slabs, at constant spacing " $l$ ", which perform a function of connectors and are rigidly fastened in the slab flanges as shown in Fig. 3.

The width of the upper flange interacting with the support $b_{p}=b_{\text {eff. } L}=b_{\text {eff.P }}$ has been assumed in the analogous manner as in the Finnish composite beam model according to which a part of the HC slab cross section of length $b_{\text {eff.L/P }}$ interacts with the beam, as a result of which
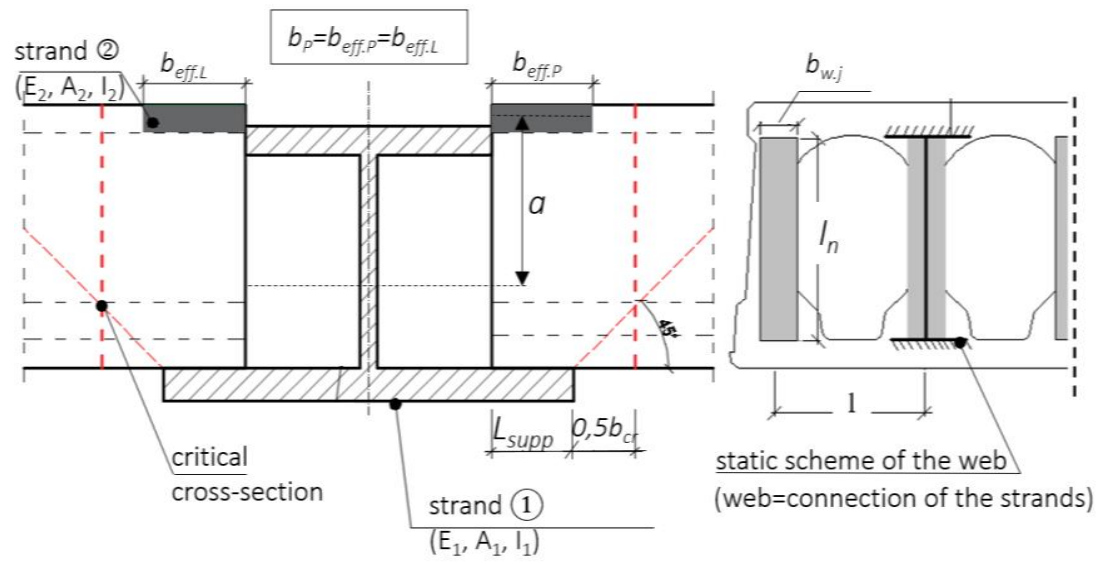

Fig. 3. Connection between bands (1) and (2). these elements have a similar state of deformation in the longitudinal direction of the support. The value of effective slab width have been determined based on tests and numerical analysis in [12], using the relationship between $L_{b}$ (distance of zero points along the support span) and $L_{b .0}$ (support span in experimental tests, $L_{b}=5.0 \mathrm{~m}$ ). Factor $b_{\text {eff. }}$, which depends on the slab height and type of the support cross section, has been determined empirically [14] and is presented in Table 1.

$b_{e f f . L / P}=\frac{b_{e f f .0}}{L_{b .0}} \cdot L_{b}$

Table 1. Values of effective width depending on the crosssection of the slab voids and on the support beam type [14]

\begin{tabular}{|c|c|c|c|c|}
\hline \multirow{2}{*}{$\begin{array}{c}\mathbf{h}_{\mathbf{s l}} \\
{[\mathrm{mm}]}\end{array}$} & \multicolumn{2}{|c|}{$\begin{array}{c}\text { Cross-section type } \\
\text { of the slab voids }\end{array}$} & \multicolumn{2}{|c|}{$\begin{array}{c}\text { Value beffo in relations to } \\
\text { support beam type }\end{array}$} \\
\cline { 2 - 5 } & oval/round & other & concrete & steel/composite \\
\hline 200 & $\mathrm{X}$ & & 150 & 80 \\
\hline 265 & $\mathrm{X}$ & & 185 & 90 \\
\hline 320 & & $\mathrm{X}$ & 270 & 100 \\
\hline 400 & & $\mathrm{X}$ & 400 & 115 \\
\hline
\end{tabular}

- Assumption 2

Compression, through neoprene pads, in the place where slabs rest on the support is sufficiently great that the slabsupport connection can be treated as an inflexible medium in the direction of the stream of interaction forces. The only flexible elements in the direction of the stream of interaction forces are slab webs. The maximum value of unit (horizontal) shear forces $\mathrm{V}_{\max }^{\prime}[\mathrm{kN} / \mathrm{m}]$ can be determined according to the formula:

$$
V_{\max }^{\prime}=\eta_{\max }^{\prime} \cdot V_{0} \cdot \frac{\psi}{\alpha^{2}}
$$

where:

$\mathrm{V}_{0}$ - maximum shear force in the support's cross section, $\eta{ }_{\max }-$ factor of max. unit forces as a function of $\alpha \cdot \mathrm{L} / 2$ $\Psi / \alpha^{2}$ - ratio characterizing the structure's geometrical and stiffness parameters

Product $\alpha \cdot \mathrm{L} / 2$ and ratio $\Psi / \alpha^{2}[1 / \mathrm{m}]$ are determined according to the formulas:

$\alpha \cdot \frac{L}{2}=\frac{L}{2} \cdot \sqrt{K_{S} \cdot\left(\frac{1}{E_{1} \cdot A_{1}}+\frac{1}{E_{2} \cdot A_{2}}+\frac{a^{2}}{E_{1} \cdot I_{1}+E_{2} \cdot I_{2}}\right)}$

$\frac{\psi}{\alpha^{2}}=\frac{\frac{a}{E_{1} \cdot I_{1}+E_{2} \cdot I_{2}}}{\frac{1}{E_{1} \cdot A_{1}}+\frac{1}{E_{2} \cdot A_{2}}+\frac{a^{2}}{E_{1} \cdot I_{1}+E_{2} \cdot I_{2}}}$

Derivation of the formula $\mathrm{V}_{\text {max }}$ along with the discussion is presented in paper [18].

Table 2a. Factor $\eta^{\prime} \max$ value (acc. to [18]).

\begin{tabular}{|c|c|}
\hline$\alpha \cdot \mathrm{L} / 2$ & $\eta^{\prime}{ }_{\max }$ \\
\hline 0.50 & 0.076 \\
\hline 0.75 & 0.154 \\
\hline 1.00 & 0.238 \\
\hline 1.25 & 0.319 \\
\hline 1.50 & 0.397 \\
\hline 1.75 & 0.462 \\
\hline 2.00 & 0.518 \\
\hline 2.25 & 0.566 \\
\hline 2.50 & 0.605 \\
\hline 2.75 & 0.640 \\
\hline $3 . \mathrm{L} / 2$ & $\eta^{\prime}{ }^{\prime}{ }^{2}$ \\
\hline 3.25 & 0.669 \\
\hline 3.50 & 0.694 \\
\hline 3.75 & 0.715 \\
\hline 4.00 & 0.750 \\
\hline 4.25 & 0.764 \\
\hline 4.50 & 0.778 \\
\hline 4.75 & 0.800 \\
\hline 5.00 & 0.800 \\
\hline 5.25 & 0.810 \\
\hline
\end{tabular}


Table 2b. Factor $\eta{ }^{\prime} \max$ value (acc. to [18]).

\begin{tabular}{|c|c|c|c|c|}
\hline$\alpha \cdot \mathrm{L} / 2$ & $\eta^{\prime}{ }_{\max }$ & - & $\alpha \cdot \mathrm{L} / 2$ & $\eta^{\prime} \max$ \\
\hline 5.50 & 0.818 & & 8.00 & 0,875 \\
\hline 5.75 & 0.826 & & 8.25 & 0,878 \\
\hline 6.00 & 0.833 & & 8.50 & 0,883 \\
\hline 6.25 & 0.840 & & 8.75 & 0,886 \\
\hline 6.50 & 0.846 & & 9.00 & 0,889 \\
\hline 6.75 & 0.852 & & 9.25 & 0,892 \\
\hline 7.00 & 0.857 & & 9.50 & 0,895 \\
\hline 7.25 & 0.862 & & 9.75 & 0,898 \\
\hline 7.50 & 0.867 & & 10.0 & 0,900 \\
\hline 7.75 & 0.871 & & & \\
\hline
\end{tabular}

The static web scheme was applied, assuming stiff connection of concrete webs with slab's upper and lower flanges, as for a bar fastened on both sides for which stiffness can be determined according to the formula:

$K_{s}=\frac{12 \cdot E_{c} \cdot I_{w}}{l \cdot l_{n}^{3}}$

where:

$E_{c}$ - slab's web modulus of elasticity $\left(E_{c}=E_{2}\right)$,

1 - axial spacing of webs, assumed substitutively as constant along the beam. Dimension "l" has been used because the joint s treated as "diffuse" on its entire length, $\mathrm{I}_{\mathrm{w}}$ - moment of inertia of a single horizontal web cross section based on the formula:

$I_{w}=\frac{b \cdot b_{w . j}^{3}}{12}$

where:

$b_{p}$ - interaction width of the slab,

$b_{w . j}$-cross section width of a single web,

$l_{n}$ - distance between surfaces that define the height of the web horizontal cross section.

Finally, the joint stiffness has the following form:

$K_{S}=\frac{E_{c} \cdot b_{p} \cdot b_{w . j}^{3}}{l \cdot l_{n}^{3}}$

Due to the system's symmetry, the connection stiffness $K_{\mathrm{s}}$ in stress calculation we can use the so-called half scheme. The value of the shear stress, understood as a ratio of maximum shear force in a single web of dimensions $b_{w . j} \cdot b_{p}$ to surface area of this web, is calculated according to the formula:

$$
\tau_{z x}=\frac{V_{\max }}{b_{w \cdot j} \cdot b_{p}} \cdot l
$$

So far, only stiffness $\mathrm{K}_{\mathrm{s}}$ of vertical joint between the upper part of the $\mathrm{HC}$ slab and the support was determined. It's possible also to take into account stiffness $\mathrm{K}^{*}$ due to the impact of the neoprene pads placed between the slabs and the support. Taking into account the impact of the pads tangential stiffness of, the joint stiffness can be described with the formula:

$$
K_{s}^{*}=\frac{K_{s} \cdot K_{n}}{K_{s}+K_{n}}
$$

where:

$\mathrm{K}_{\mathrm{n}}$ - neoprene tape/pad stiffness.

In case $K_{n} \geq K_{s}, K^{*} \approx K_{s}$ should be assumed.

In the remaining part, the model developed by the authors is based on the Finnish model, but it assumes implementation of the aforementioned two-beam method for determination of horizontal tangential stress $\tau_{\mathrm{xz}}$. All remaining rules of determination of components of the main tensile stress $\sigma_{1}$, and the destruction criterion itself, are identical as in [14].

\section{Comparative analysis of existing computational models}

A comparative analysis has been performed in order to compare and find relationships between the values of transversal shear stress $\tau_{\mathrm{zx}}$ determined with the authors' model and with the Finnish model (fib recommendation [14]). The analysis was performed for $200 \mathrm{~mm}, 320 \mathrm{~mm}$ and $500 \mathrm{~mm}$ thick (nominal thickness) slabs resting on an IFB steel support. The analysis also accounted for the effect of a $60 \mathrm{~mm}$ thick reinforced concrete topping layer. The obtained results of calculations are presented in Fig. 4.

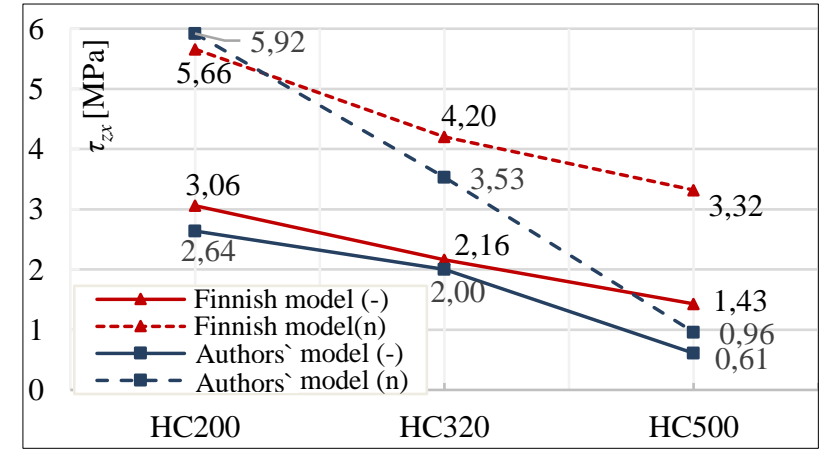

Fig. 4. Horizontal shear stress $\tau_{\mathrm{zx}}$ according to the Finnish and authors' model. Symbols (-) and (n) are assigned to cases without and with reinforced concrete topping layer.

Verification of assumptions of the authors' model involved also a comparative analysis with the results of experimental tests carried out by Hegger's and Roggendorf's team in Aachen, Germany [15]. The analysis included 2 from among 8 tests performed on the floor field consisting of ten HC slabs: extruded elements MV5/265 in case one, and VMM VSD 25 elements manufactured using the slip-form technology in case two. The floors (without concrete topping, filling of cores, circumference ties, and mechanical confinement of the displacement along the support axis) rest on steel IFB supports of total span equal to $6.4 \mathrm{~m}$. The load was applied in a linear manner at the distance from the axis of support 
equal to 2.5 times of the HC slabs' height.

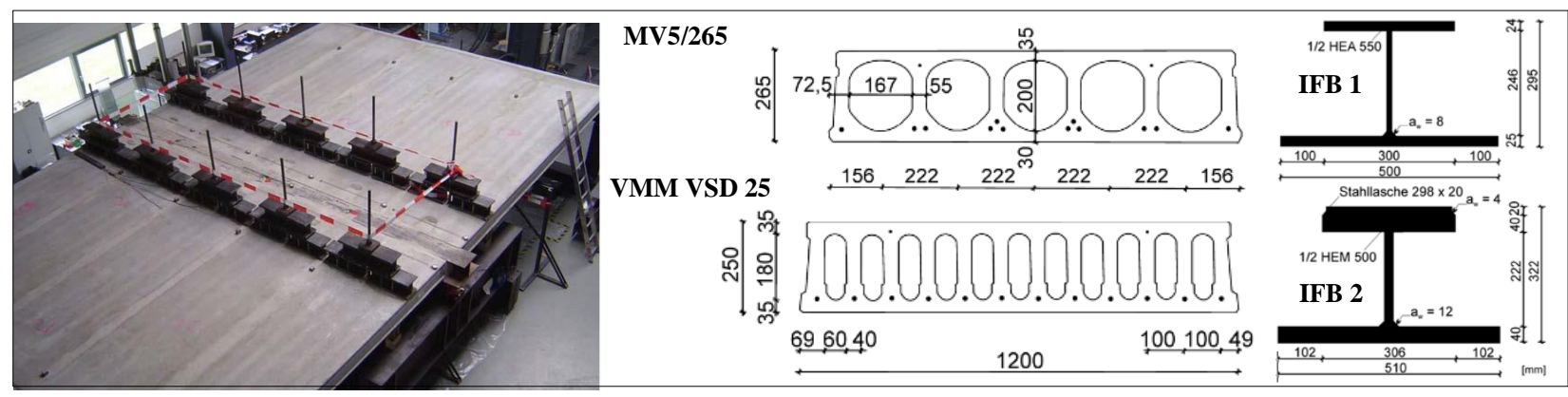

Fig 5. View of the test stand and cross-sections of the HC slabs and support beams taken in research [15].

The tests stand and geometry of tested elements are presented in Fig. 5.

Results of the comparative analysis are given in Table 3.

Table 3. Results of the comparative analysis of the experimental research with the German and authors computational models.

\begin{tabular}{|c|c|c|c|c|}
\hline & \multicolumn{3}{|c|}{ Hegger-Roggendorf } & \multirow{3}{*}{$\begin{array}{c}\text { Authors` } \\
\text { model }\end{array}$} \\
\hline & \multicolumn{2}{|c|}{ Tests } & \multirow{2}{*}{$\begin{array}{c}\text { German } \\
\text { model }\end{array}$} & \\
\hline & $\begin{array}{c}\text { rigid } \\
\text { support }\end{array}$ & $\begin{array}{l}\text { flexible } \\
\text { support }\end{array}$ & & \\
\hline Test 1 & $239 \mathrm{kN} / \mathrm{m}$ & $141 \mathrm{kN} / \mathrm{m}$ & $135 \mathrm{kN} / \mathrm{m}$ & $115 \mathrm{kN} / \mathrm{m}$ \\
\hline Test 2 & $266 \mathrm{kN} / \mathrm{m}$ & $158 \mathrm{kN} / \mathrm{m}$ & $149 \mathrm{kN} / \mathrm{m}$ & $126 \mathrm{kN} / \mathrm{m}$ \\
\hline
\end{tabular}

\section{Conclusions}

Based on the computational analysis related to the results of experimental studies carried out on a real scale, the following conclusions can be made:

- for all cases without concrete topping, the values of transversal shear stress $\tau_{\mathrm{zx}}$ obtained using the authors' model are lower than according to the Finnish model, and the difference between the models is about $25 \%$ (minimum about $10 \%$ and maximum about $60 \%$ ). In elements with concrete topping, a similar relationship is maintained for medium slabs (HC320) and thick slabs (HC500), with average difference of about $45 \%$. In the HC200 slab, in which the concrete topping increases the floor height by as much as $30 \%$ resulting in a large increase of bending stiffness of the slab-support composite system, at small web thickness, the results from both models differ slightly. The calculation analysis indicates that the relationship of the $\tau_{\mathrm{zx}}$ stress values according to both models is strongly dependent on the slab thickness, and hence on flexibility of its webs;

- both the authors' model and the Finnish model indicate an approximately $50 \%$ increase of transversal shear stress $\tau_{\mathrm{zx}}$ due to reinforced concrete topping. This is caused by the fact that the authors' approach applies the same rule for determination of the slab width interacting with the support;

- the comparison of use of the HC slabs' shear capacity according to the authors', Finnish and German models indicates that the values obtained in the authors' model are on the average about $12 \%$ less than in the Finnish model, and the relationship with the German model depends on the slab thickness. The results for thin and medium slabs are greater by $34 \%$ and $15 \%$, respectively. For thick slabs, however, the effort of shear capacity is about $10 \%$ less than in the German model that does not account for the web flexibility;

- the authors' model gives results that are in between the Finnish model and the German model, which seems justified due to the conservative character of the Finnish model. The authors' approach is the first attempt to date at analytical consideration of the webs flexibility which, as it turned out, can have a significant impact on maintaining the adequate capacity of a hollow core slab. In the remaining models, the webs are treated as a rigid system that connects horizontal flanges of the slab;

- the analysis of results obtained in German experimental tests indicates that actual linear load at slab failure is about $19 \%$ greater than the results obtained with the authors' model, and 5\% greater than the estimate obtained according to the German model. It should be emphasized, however, that the difference between the two approaches which reaches about $14 \%$ is relatively small and puts the authors' model on the safe side;

- the analysis also takes into account use of continuous neoprene pads between the slab and the support. The impact of support flexibility due to the use of pads gives the $\tau_{\mathrm{zx}}$ stress values $2 \div 3$ times less than without pads. Such a large reduction of the undesirable horizontal shearing effect would be possible only in case of absence of any additional constraints of the floor slab. In reality, the favourable effect of neoprene pads is significantly reduced by stiffening of the $\mathrm{HC}$ slab caused by concreting its face in the floor tie. The presence of the ties substantially limits the slab deformation. The experimental tests of floor systems [15], with and without pads, did not show the noticeable increase of slab shear capacity due to the presence of neoprene.

\section{References}

1 M. Surma, W. Derkowski, Projektowanie stropów prefabrykowanych na wiotkich podorach, Inżynieria i Budownictwo, 3/2018, 138-141, (2018)

2 M. Surma, Nośność na ścinanie strunobetonowych plyt kanałowych, $z$ uwzględnieniem nadbetou, 
opartych na podporach podatnych, $\mathrm{PhD}$ Thesis, Cracow University of Technology, Poland (2018)

3 K. Flaga, W. Derkowski, M. Surma, Concrete strength and elasticity of precast thin-walled elements, Cement, Wapno, Beton, 21 (5), 310-317 (2016)

4 P. Bodzak, Ł. Sowa, Badania wptywu podatności podpór na nośność sprężonych plyt kanałowych, JCEEA, 63 (2016)

5 W. Derkowski, M. Surma, Torsion of precast hollow core slabs, Technical Transactions. Civil Engineering, 3-B, 112, 31-43 (2015)

6 W. Derkowski, M. Surma, Shear capacity of prestressed hollow core slabs on flexible supports, Technical Transactions. Civil Engineering, 2-B, 110, 3-12 (2015)

7 W. Derkowski, M. Surma, Complex stress state in prestressed hollow core slabs, in Recent Advances in Civil Engineering: Building Structure, Cracow University of Technology Monography 478, 11-27 (2015)

8 W. Derkowski, Niezamierzony efekt częściowego zamocowania stropów ze sprężonych płyt kanałowych, Przegląd Budowlany, 1, 24-27 (2014)

9 J. Szulc, Projektowanie prefabrykowanych konstrukcji zespolonych z uwzględnieniem podatności styku i elementów podporowych, ITB (2012)

10 EN 1168+A3: Precast concrete products - Hollow core slabs, (2011)

11 M. Pajari, VTT 148, Prestressed hollow core slabs supported on beams. Finnish shear tests on floors in 1990-2006, (2010)

12 M. Pajari, VTT 1587, Shear capacity of hollow core slabs on flexible supports, (1994)

13 Code Card 18: Design of hollow core slabs supported on beams, (2007)

14 fib Bulletin 6, Special design considerations for precast prestressed hollow core floors, (2000)

15 T. Roggendorf, Zur Tragverhalten von SpannbetonFertigdecken bei biegeweicher Lagerung, $\mathrm{PhD}$ Thesis, Aachen Technische Hochschule (2010)

16 Industrierichtlinie Spannbeton-Fertigdecken VMM Spannbetonplatten (2017)

17 A. Cholewicki, J. Szulc, Pasmowy model wobliczeniach konstrukcji zespolonej belka-plyty stropowe, , ITB, 35/2, (2001)

18 A. Cholewicki, Konstrukcje zespolone z prefabrykatów, Monography, ITB (2001) 